\title{
Spectral Integration of Interaural Time Differences in Auditory Localization
}

\author{
Le Goff, Nicolas; Buchholz, Jorg M.; Dau, Torsten
}

Publication date:

2013

Link back to DTU Orbit

Citation (APA):

Le Goff, N., Buchholz, J. M., \& Dau, T. (2013). Spectral Integration of Interaural Time Differences in Auditory Localization. Poster session presented at 21st International Congress on Acoustics, Montreal, Canada.

\section{General rights}

Copyright and moral rights for the publications made accessible in the public portal are retained by the authors and/or other copyright owners and it is a condition of accessing publications that users recognise and abide by the legal requirements associated with these rights.

- Users may download and print one copy of any publication from the public portal for the purpose of private study or research.

- You may not further distribute the material or use it for any profit-making activity or commercial gain

- You may freely distribute the URL identifying the publication in the public portal

If you believe that this document breaches copyright please contact us providing details, and we will remove access to the work immediately and investigate your claim. 
Introduction

The communication skills of normal-hearing persons in complex accustical environments are

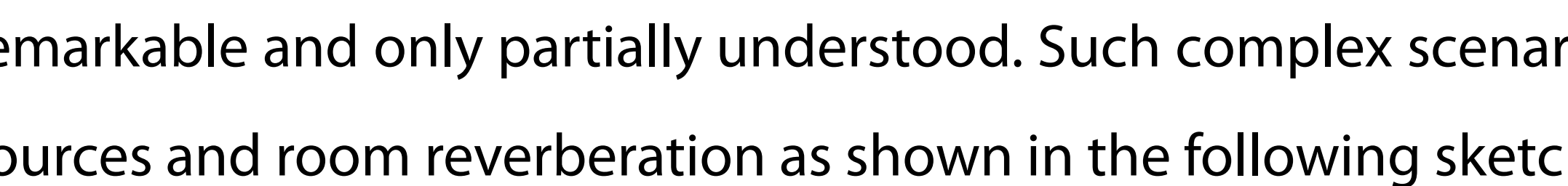

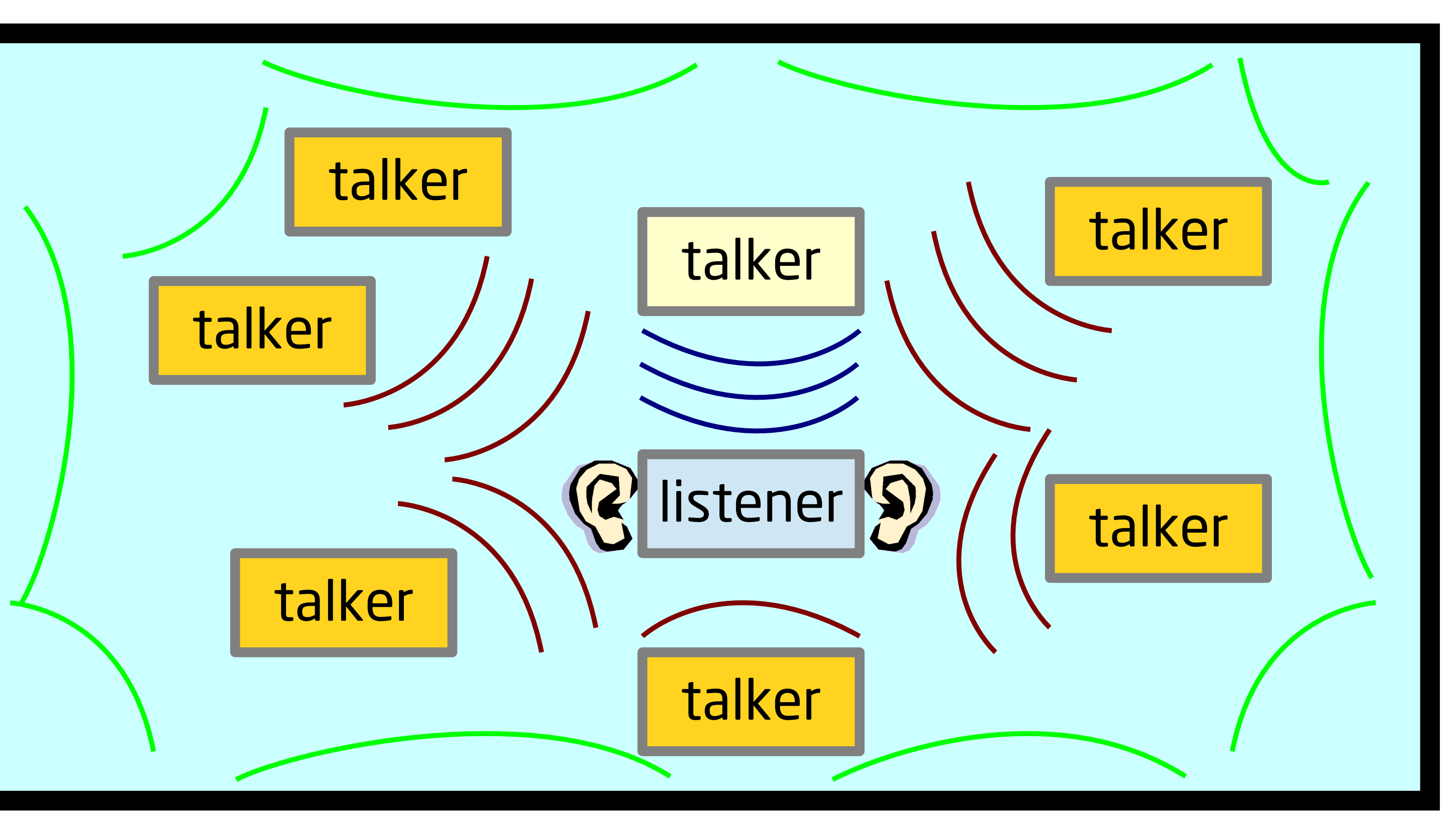

Several studies have shown that the ability to communicate (listen) in realistic environment ss supported by localization cues (e.g, Bronkhorst, 2000). Localization in controlled conditions has equencies. However, many aspects of realistic acoustical scenarios can affect the processing of ITD in localization tasks:

- Hard surfaces (walls, celing, floor, furniture..) cause reverberation, which leads to a decrease of .

azimuth angle (reference IT) (Hafter 1975 . TDS might be influenced by room reverberation and sound source azimuth angle. Models of spectral weighting and integration of IIIS have been proposed in previous studies le.s. Faatgever, 1980, Stern et al.1988, Shackleton et al. 1992). However the effect of realistic listening

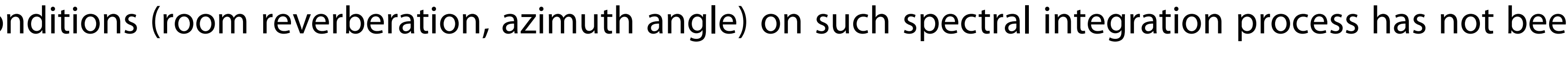
studied in detal

Research Question
How ITD-based localization is influenced by realistic How ITD-based localiz
acoustical conditions?

This study investigated the influence of room reverberation and azimuth angle on ITP-based Iocalization for broadband signals. A free-pointing localization experiment with broadband signals was conducted, in which the IC and the ITD values were varied. A conceptual model to predict the riv-based Iocalization in realistic conditions is proposed. The model assumes a spectrad optimal spectral integration of information after spectral weighting. The spectral weighting was using the concept of signal detection theory

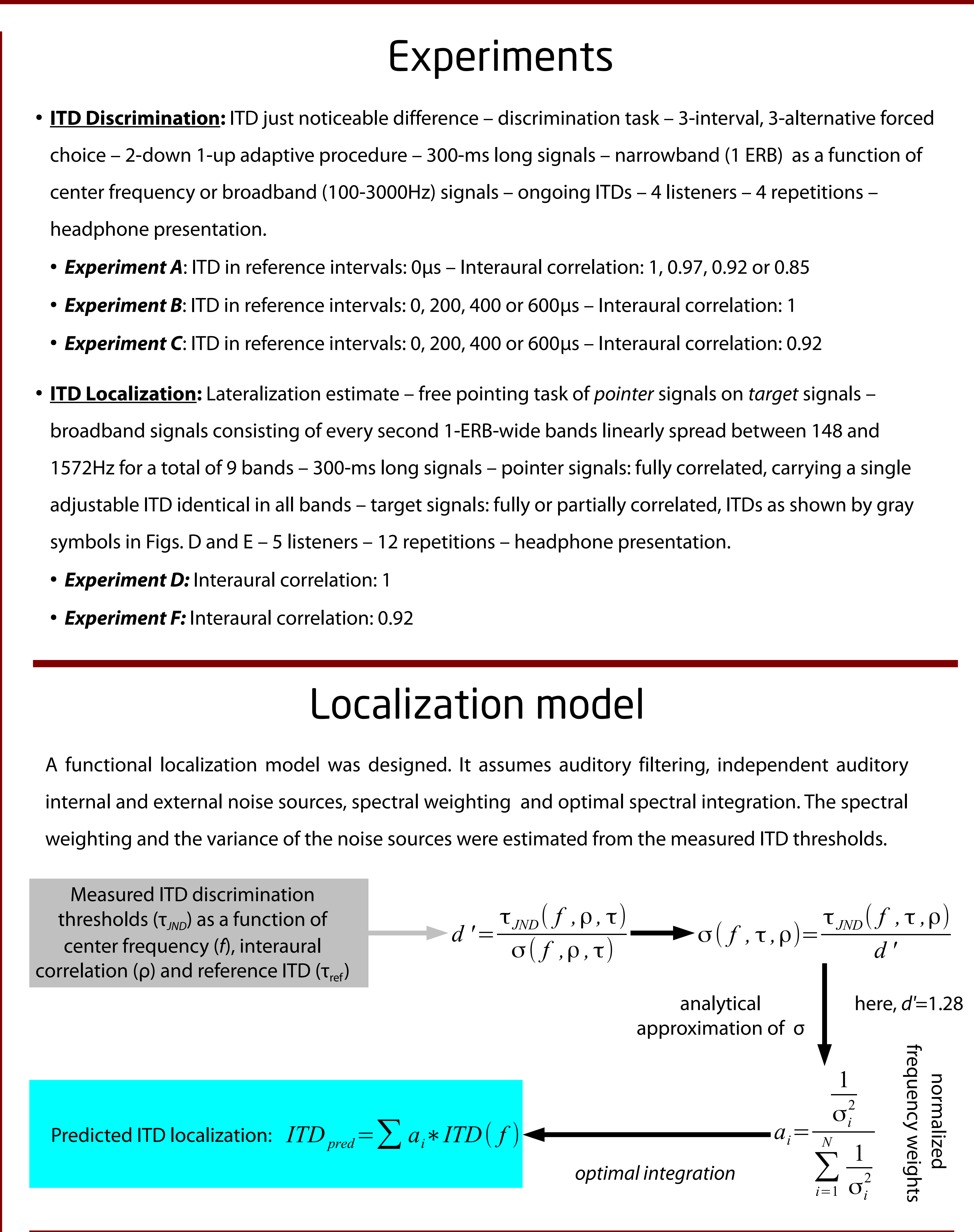

ITD discrimination fitting

The variance, $\sigma^{2}$ used in the above localization model was derived by fitting analytical functions to the

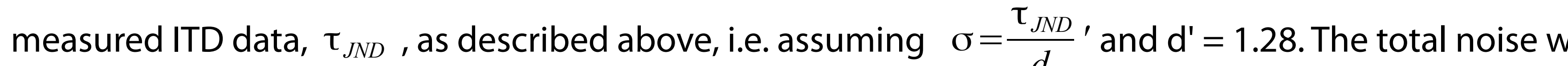
thereby described by two independent noise sources, i.e: $\sigma^{2}=\sigma_{\text {iemenal }}^{2}+\sigma_{\text {elumal }}^{2}$

$$
\begin{aligned}
& \sigma_{\text {inemana }}^{2}(f, \tau)=g_{\text {imenal }}(\tau) \cdot\left(\frac{1}{B_{E R B}(f) \cdot f}\right) \cdot\left(1+\frac{f}{f_{\text {inemal }}(\tau)}\right)
\end{aligned}
$$

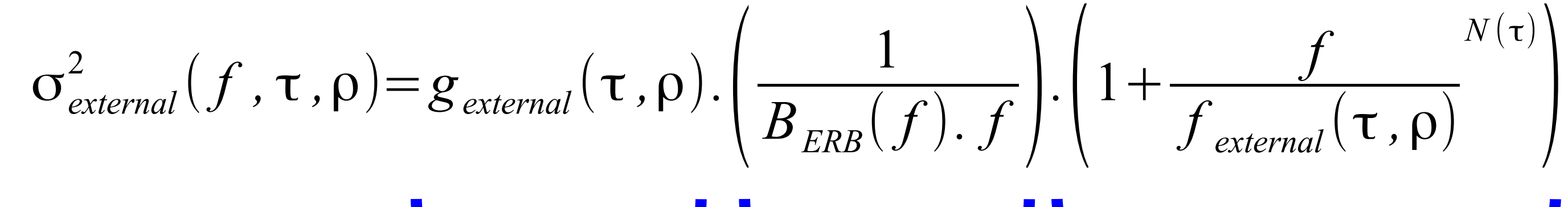

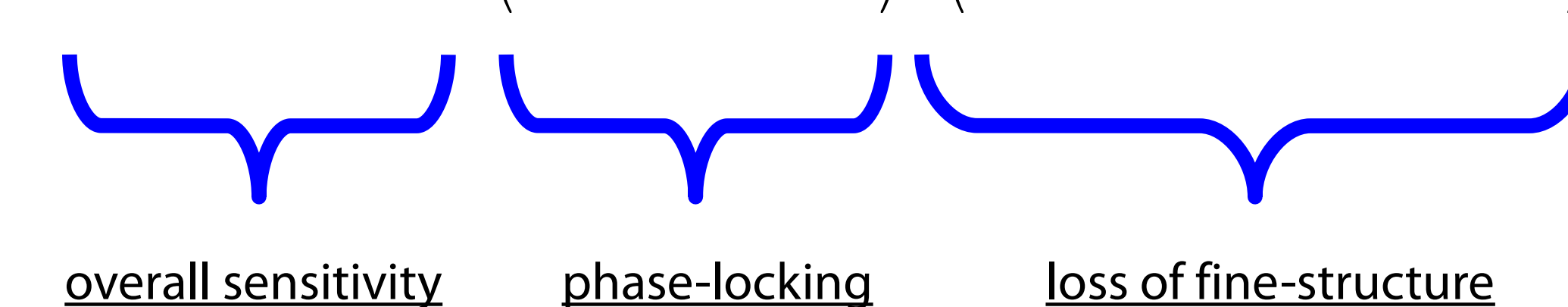



Data \& predictions - Lateralization
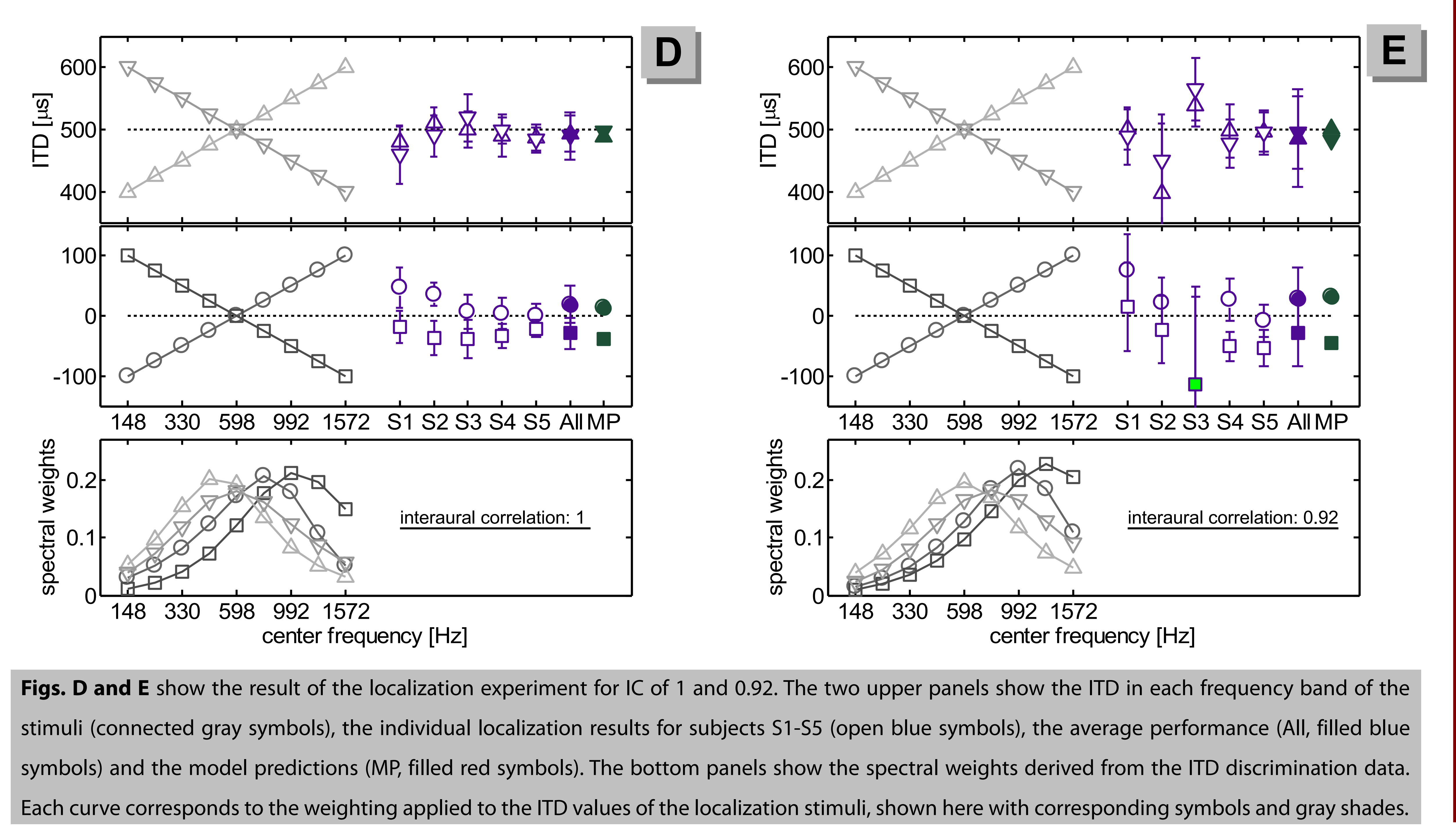

E

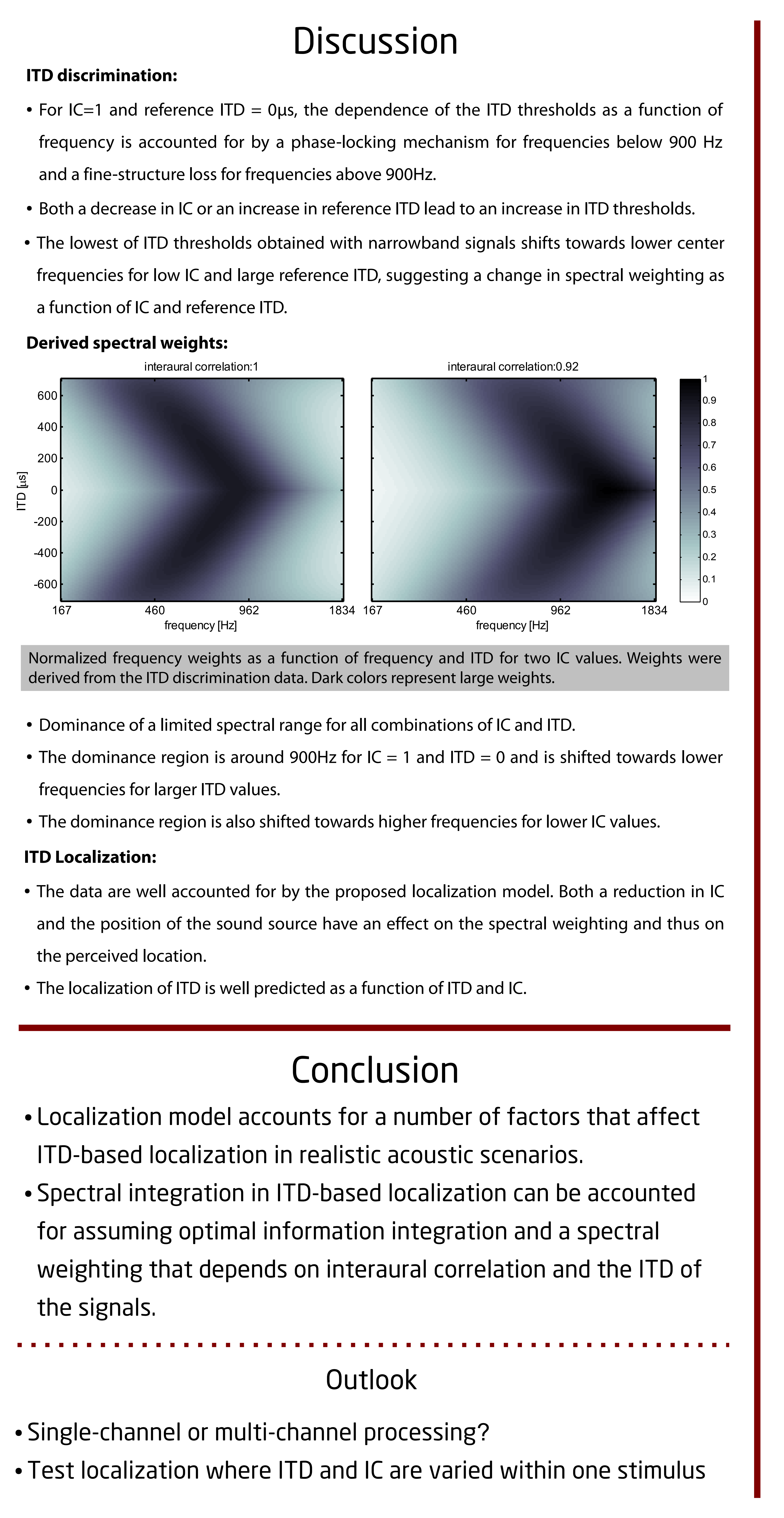

